\title{
autêntica
}

ARTIGOS

\section{“O INÍCIO É ATÉ MEIO ASSUSTADOR (...)!": INQUIETAÇÕES DOCENTES PELA ÓTICA DE PROFESSORAS INICIANTES}

Ingrid Cristina Barbosa FERNANDES Universidade Federal do Rio de Janeiro - UFRJ

Rio de Janeiro, RJ-Brasil ingridfernandes.jc@gmail.com orcid.org/0000-0003-1061-4973

Giseli Barreto da CRUZ Universidade Federal do Rio de Janeiro - UFRJ

Rio de Janeiro, RJ-Brasil cruz.giseli@gmail.com orcid.org/0000-0001-5581-427X

RESUMO: $O$ artigo trata da inserção profissional docente, tendo por objetivo compreender como inquietações de professores alfabetizadores afetam a sua docência no transcorrer da inserção profissional. Orientado pela pesquisa narrativa, articula as vozes de seis docentes, reconhecidas a partir dos dados obtidos com a aplicação de um questionário aos egressos de um curso de Pedagogia de uma instituição universitária. As narrativas foram construídas com base em entrevista, referenciadas por Galvão e Passeggi, Souza \& Vicentini, e discutidas com o apoio de autores que tratam do desenvolvimento profissional docente, dentre eles: Alarcão \& Roldão; Marcelo e Cochran-Smith. As constatações indicam, de um lado, que as inquietações se relacionam com a complexidade de lidar com a heterogeneidade das turmas, a resolução de conflitos e as cobranças pessoais; de outro, a potência da troca entre os pares como forma de enfrentamento das inquietações, que apesar de interpelar, não paralisa as docentes.

Palavras-chave: Inserção profissional docente. Inquietações docentes. Desenvolvimento profissional docente. 


\title{
“THE BEGINNING IS THROUGH THE SCARY (...)!”: TEACHERS 'QUESTIONS FROM THE PICTURE OF INITIATING TEACHERS
}

\begin{abstract}
The article deals with the professional insertion of teachers, aiming to understand how concerns of literacy teachers affect their teaching in the course of professional insertion. Guided by narrative research, it articulates the voices of six teachers, recognized from the data obtained with the application of a questionnaire to graduates of a Pedagogy course at a university institution. The narratives were constructed based on an interview, referenced by Galvão and Passeggi, Souza \& Vicentini, and discussed with the support of authors who deal with teacher professional development, among them: Alarcão \& Roldão; Marcelo and Cochran-Smith. The findings indicate, on the one hand, that the concerns are related to the complexity of dealing with the heterogeneity of classes, conflict resolution and personal charges; on the other hand, the power of exchange between peers as a way of coping with concerns, which despite questioning, does not paralyze teachers.
\end{abstract}

KEYWORDS: Teachingprofessionalinsertion. Teachingconcerns. Teacherprofessionaldevelopment.

\section{“EL COMIENZO ES INCLUSO UN POCO ATERRADOR (...)!”: ENSEÑAR PREOCUPACIONES DESDE LA PERSPECTIVA DE LOS MAESTROS PRINCIPIANTES}

RESUMEN: El artículo trata sobre la inserción profesional del profesorado, con el objetivo de comprender cómo las inquietudes de los alfabetizadores afectan su docencia en el transcurso de la inserción profesional. Guiado por una investigación narrativa, articula las voces de seis docentes, reconocidas a partir de los datos obtenidos con la aplicación de un cuestionario a egresados de un curso de Pedagogía en una institución universitaria. Las narrativas se construyeron a partir de una entrevista, referenciada por Galvão y Passeggi, Souza \&Vicentini, y discutida con el apoyo de autores que se ocupan del desarrollo profesional docente, entre ellos: Alarcão\&Roldão; Marcelo y Cochran-Smith. Los hallazgos indican, por un lado, que las preocupaciones están relacionadas con la complejidad de lidiar con la heterogeneidad de clases, resolución de conflictos y cargos personales; por otro lado, el poder del intercambio entre pares como forma de afrontar inquietudes, que a pesar de ser cuestionadas, no paraliza a los docentes.

PALABRAS CLAVE: Inserción profesional docente. Enseñanza de preocupaciones.

Desarrollo profesional docente. 


\section{Introdução}

O presente artigo tem por objetivo discutir a temática da inserção profissional pela lente das inquietações docentes de professoras iniciantes, recém egressas de um curso de Pedagogia, que, ao assumiram a docência, foram designadas para turmas de alfabetização. A análise é sustentada por uma pesquisa que buscou compreender como inquietações de professores alfabetizadores afetam a sua docência no transcorrer da inserção profissional. O fio condutor foram as narrativas docentes, compreendidas como um processo que não busca uma verdade, mas os sentidos que os sujeitos atribuem e elaboram para suas vivências. No contexto do artigo, abordaremos mais especificamente as inquietações acerca da inserção profissional e a troca entre pares como forma de enfrentamento.

No âmbito epistemológico da formação de professores, o estudo sustentou-se na compreensão do desenvolvimento profissional docente enquanto uma construção do eu profissional, modificada ao longo da carreira. É influenciado por distintos fatores, como a escola, contextos políticos, crenças, valores, conhecimentos e experiências, tal como argumentam André (2018), Alarcão \& Roldão (2014) e Marcelo (2009). A terminologia "desenvolvimento profissional" é escolhida a partir do sentido de continuidade que a palavra "desenvolvimento" traz, objetivando transpor as justaposições entre formação inicial e formação contínua dos professores.

Compreendemos a inserção profissional, segundo Tardif e Raymond (2002), Marcelo (1999) e Cochran-Smith (2003), como um período significativo na formação do professor, visto que nesta etapa ocorrem aprendizagens intensas e os professores lidam com o chamado "choque do real", fase na qual há o enfrentamento de múltiplos desafios, como o conhecimento da realidade escolar, o desenvolvimento de sua identidade profissional e as particularidades da escola em que o docente está inserido. Este momento peculiar pode ser reconhecido por vários fatores, dentre os quais, sobrelevam-se: o isolamento, uma vez que via de regra os professores não dispõem de espaços para partilharem suas práticas de modo institucionalizado e, por isso, acabam realizando trocas de modo informal ou - em alguns casos - se isolam; inseguranças, preocupações e tensões; aprendizagens intensas que ocorrem, em grande parte, por tentativa e erro; preocupação com o domínio do conteúdo e domínio de turma; choque com a realidade, isto é, a reação docente a partir da idealização do cotidiano e a realidade encontrada; balanceamento entre expectativas elaboradas ao longo da formação inicial e em experiências anteriores e a realidade encontrada na inserção profissional.

Tendo isso em mente, interessou-nos olhar de forma mais detida para as inquietações docentes de professores em inserção em turmas de alfabetização. A opção pelo vocábulo "inquietações" reside na proposta de analisá-la não apenas enquanto dificuldade, mas em observar suas formas de enfrentamento e refletir sobre a potência delas no processo de formação docente.

Ao procurar delimitar o que compreendemos por inquietações, nos dirigimos à Filosofia, que define inquietações ou inquietudes como o mal-estar da "necessidade insatisfeita". O presente trabalho se aproxima de tal perspectiva, uma vez que, compreendemos a inquietação como incômodo que impulsiona e não que paralisa. A ideia de inquietação que norteia este trabalho não volta os olhos para o bem esperado, de modo a ser superada; mas confere a tônica ao mal-estar, atentando para suas nuances e dimensões. Desse modo, ao se tratar da inquietação do docente em situação de inserção, podemos defender que não se trata, necessariamente, de enfocar uma tipologia ideal de formação do professor, mas de analisar o próprio mal-estar, compreendendo a potência das inquietações para refletir sobre a formação do professor. Nesse sentido, o que entendemos por inquietação está mais para o desejo, do que para a apatia, está mais para o motriz do que para a paralisação, está mais para a potência do enfrentamento do que para a estagnação. 
Nessa direção, a pesquisa teve por objetivo compreender como inquietações de professores em turmas de alfabetização afetam a sua docência durante seu período de inserção profissional. Buscamos realizar um recorte enfocando na inserção de professoras em turmas do primeiro ao terceiro ano dos anos iniciais do Ensino Fundamental. Essa escolha se fundamenta na Resolução CNE/CEB número 7 de 14 de dezembro de 2010 que em seu artigo 30 menciona que os três anos iniciais do ensino fundamental deverão assegurar a alfabetização e o letramento.

Para fins deste artigo, procuraremos discutir as duas inquietações mais recorrentes entre as docentes, enfocando a inserção profissional e a forma de enfrentamento mencionada por todas as professoras participantes da pesquisa. Compreendemos este momento de inserção como catalisador de inquietações plurais, sobretudo, se acrescidas das inquietações acerca do processo de alfabetização.

Metodologicamente o estudo se estruturou pela via da pesquisa narrativa, compreendendo-a como Galvão (2005) explicita: como método de investigação, pressupondo uma interação entre investigador e participantes; como processo de reflexão pedagógica, propiciando que a medida que o professor conte suas experiências possa sobre elas refletir e aventar novas possibilidades de atuação, problematizando sua prática e avaliando-a; como processo de formação, destacando a relação entre investigação e formação, confrontando saberes diversos vinculados a vivências personalizadas.

Fundamentados nesta perspectiva, seguimos um percurso metodológico que abarcou, inicialmente, a aplicação de um questionário exploratório para identificar os possíveis sujeitos da pesquisa, egressos do curso de Pedagogia da Faculdade de Educação da Universidade Federal do Rio de Janeiro (FE/UFRJ-BR). Os questionários foram encaminhados por meio do Sistema Integrado de Gestão Acadêmica para os egressos entre os anos de 2016 e 2018, de modo a mapear os sujeitos a partir do critério que atendia ao objetivo da pesquisa, a saber: estar atuando como docente, de um mês até cinco anos, em turmas do primeiro ao terceiro ano do primeiro segmento do ensino fundamental no contexto de escolas públicas. A análise do questionário nos permitiu identificar seis professoras, que, uma vez contactadas, aceitaram participar da pesquisa. $\mathrm{Na}$ sequência, voltamo-nos para a realização de entrevistas narrativas com as seis professoras localizadas, de modo a conhecer as inquietações dos sujeitos neste período de inserção profissional. As questões versavam sobre a inserção profissional, desafios e formas de enfrentamentos bem como dos desafios de ingressar na profissão docente atuando em turmas do ciclo de alfabetização.

As professoras participantes foram nomeadas com as primeiras letras do alfabeto, no sentido de manter o anonimato, preconizado no registro de consentimento livre e esclarecido. Desse modo, a partir de agora, as chamaremos de Professora A, Professora B, Professora C, Professora D, Professora E e Professora F, cuja ordem das letras foi estabelecida pela sequência em que as entrevistas foram realizadas. Das professoras entrevistadas, três (professoras B, C e D) atuavam na Rede Municipal de Educação do Rio de Janeiro (SMERio) na condição de servidoras da Prefeitura Municipal do Rio de Janeiro; duas (professoras A e F) atuavam no Colégio de Aplicação da UFRJ (CAp UFRJ) e uma (professora E) no Colégio Pedro II (CPII), sendo estas três servidoras federais.

As narrativas nos permitiram analisar a inserção profissional docente em turmas de alfabetização, considerando, de um lado, as inquietações referentes à responsabilidade diante do processo ensino-aprendizagem da leitura e escrita; de outro, as inquietações relacionadas à inserção propriamente e as estratégias mobilizadas para o seu enfrentamento. Com base na análise empreendida, organizamos este artigo em torno de três seções: a primeira se debruçará sobre as principais inquietações que afetam as professoras iniciantes; a 
segunda sobre a relação entre a idealização e a prática da docência; e a terceira, as formas de enfrentamento dos desafios da inserção profissional.

\section{“Eu fui pra casa pensando: o que que eu vou fazer?"}

Distintos autores têm explorado as dificuldades decorrentes do confronto inicial com a realidade profissional, como Alarcão e Roldão (2014); Cochran-Smith (2012); Marcelo (1999); Lima (2007) e Huberman (1995). Esses têm compreendido a inserção profissional como um período de relevância para a permanência ou abandono da docência, bem como para a construção da identidade profissional dos sujeitos.

Alarcão e Roldão (2014) salientam que os professores em formação têm idealizações sobre a docência que são construídas em momentos variados como suas vivências enquanto alunos, em suas particularidades e na formação inicial. Ao ingressarem na carreira lidam com demandas plurais decorrentes de seu ofício. Nesse sentido, precisam balancear o idealismo forjado em suas múltiplas experiências e o realismo do cotidiano profissional.

Tendo isso em mente, no decorrer da entrevista estimulamos as participantes a falarem sobre o início da carreira. Sobre como foi e estava sendo assumir-se enquanto profissional docente responsável pela aprendizagem da leitura e da escrita de crianças no ciclo inicial do ensino fundamental. Que questões as interpelavam e se constituíam em fonte de inquietações? Para se referir às inquietações, as professoras recorreram a expressões que nos propiciaram reflexões importantes sobre a necessidade de atenção a esse período peculiar da trajetória dos sujeitos, corroborando com que a literatura da área tem discutido.

À guisa de sistematização, apresentamos no quadro $n^{\circ} 01$ as expressões mais recorrentes nas narrativas das professoras participantes da pesquisa sobre seus processos de inserção profissional.

\section{Quadro no o1. Inserção: Perspectivas e expressões:}

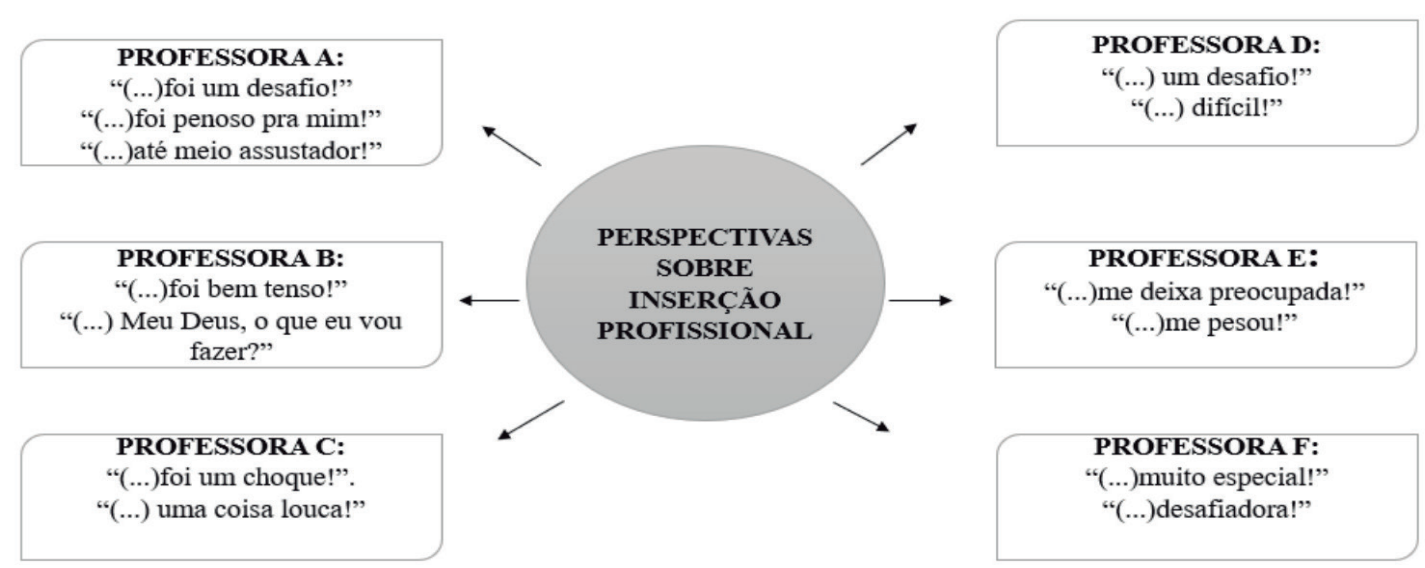


Tal como se pode notar, é possível perceber por meio das expressões docentes a dimensão desafiadora deste período. A professora " $F$ " salienta sua inserção como "especial" em virtude das trocas que são realizadas, aspecto que analisaremos mais adiante. Embora tenha esse caráter "especial" a docente não deixa de destacar a complexidade deste período, que a despeito de não ser definitivo e único determinante na carreira docente, deixa nela marcas indeléveis.

Há uma série de dificuldades enfrentadas pelos professores em início de carreira, Alarcão e Roldão (2014) as organizam em quatro ordens de dificuldades: i- de ordem científico pedagógica, tais como gestão do ensino, problemas de indisciplina e desmotivação, diferenciação de ritmos de aprendizagem, gestão do currículo, relacionamento com os alunos, avaliação; ii- de ordem burocrática, como conhecimento da legislação, dos regulamentos, do funcionamento da escola, diversidade de tarefas e tempo para as gerir, assunção de cargos sem preparação; iii- emocional, que compreende autoconhecimento, autoestima e autoconfiança, isolamento, angústias, gestão das dimensões pessoal e profissional e iv- de ordem social, abarcando identidade e identificação profissional, relacionamento com os colegas, desconhecimento das regras de conduta, relacionamento com os encarregados de educação.

No âmbito das complexidades de ordem científico-pedagógica as professoras apresentaram algumas inquietações centrais no que tange ao manejo das turmas, salientando três aspectos: o comportamento dos alunos, elevado número de alunos por turma e a heterogeneidade, sobretudo no que tange a alfabetização.

Era uma turma bastante complicada, assim... Já era uma turma que tinha um histórico na escola de ser uma turma muito agitada assim tal... com esse perfil, então assim é... até eu construir... eu conseguir construir essa relação com eles assim foi... foi complicado. (Professora A - 16/04/2019)

Eu cheguei com aquela realidade, aquele monte de criança... É complicado. Crianças com diferentes níveis dentro da mesma sala. E é difícil porque eles são pequenos, então assim, você tem que preparar atividade pra um, prepara uma atividade pra outro, aquele dali avança até onde o outro não avança. E isso dificulta bastante também. (Professora B - 18/04/2019)

A preocupação com os ritmos distintos de aprendizagem foi a mais citada nas narrativas docentes. Lima (2007) apresenta que a maior complexidade no que tange à aprendizagem dos alunos se concentra na diferenciação dos ritmos, desencadeando forte ansiedade e tensão nos docentes, uma vez que é preciso descontruir uma concepção de que a aprendizagem decorre de modo imediato ao ensinar e que a homogeneidade das turmas é o ideal para o desenvolvimento do trabalho pedagógico.

O processo de alfabetização é complexo e demanda um movimento de reflexão em torno da aprendizagem da leitura e da escrita vinculada à heterogeneidade dos processos, dos sentidos e das culturas, tal como aponta Goulart (2014) pautada nos pressupostos Bakthinianos.

As crianças não possuem uma concepção homogênea da natureza da leitura e da escrita, seu percurso de construção do objeto textual é peculiar e próprio de cada uma delas (GOULART, 2000). Nesse sentido, enquanto docentes não podemos pensar em formulações de práticas uniformes para atender à pluralidade. Reconhecer a importância da heterogeneidade com a qual o professor lida cotidianamente não minimiza a complexidade de trabalhar com essa característica, aspecto que foi evidenciado nas narrativas das docentes acerca do que lhes inquietava. 
Ao mencionarem a heterogeneidade como fator de inquietação as docentes evidenciaram que o sentido dessa inquietação não era silenciar a pluralidade ou homogeneizar o diverso, mas aventar possibilidades de trabalho que colaborem com a aprendizagem de todos os educandos e de cada um, isto é, de todos os discentes, sem desconsiderar a potência do plural.

A partir dessas vivências o professor iniciante possui aprendizagens intensas e oriundas de distintas trocas, além de começar a desenvolver um sentimento de responsabilidade com a "sua turma" e "seus alunos". Nesse período de ingresso na carreira docente o professor experimenta sentimentos e aprendizagens plurais que serão significativas na construção de seu "eu profissional". Analisar sua própria experiência e percurso é fundamental neste processo, não que haja uma linha de chegada no sentido de se tornar o "modelo de professor", mas considerando que há um caminho de construção cotidiana que precisa ser acompanhado, refletido e valorizado, percebendo os avanços, dificuldades, enfrentamentos e - assim - constituindo-se na teia do cotidiano.

Então, o começo foi muito difícil, eu digo que ... é... eu errei muito com essa turma, porque eu não soube ensinar, de fato. Eu tive que gerir tantos conflitos... eu separava briga o dia inteiro! Eles, né, como ocorrem casos até hoje, agrediam a gente. Eu já apanhei de aluno, de separar briga e ser mordida, então, assim... é... foi muito difícil o primeiro ano! (Professora C - 21/06/2019.).

As narrativas docentes deixam perceber as aprendizagens e desafios vivenciados no período de ingresso na profissão docente, sinalizando-nos a necessidade de um olhar atento e esforços conjugados para auxiliar professores iniciantes, de modo sistemático e intencional, propiciando um processo de inserção profissional como fonte profícua de construção de conhecimento, de modo que os desafios não se tornem causa de reproduções de reações de modo não crítico ou elementos que impedem o desenvolvimento profissional, mas que se tornem fonte de ação refletida que reverberará no favorecimento da aprendizagem do educando.

Assim, a inserção profissional se constitui como um importante e desafiador período do processo de desenvolvimento profissional do professor que precisa ser assistido para além de iniciativas informais de acompanhamento de modo que o balanceamento entre as idealizações e a realidade do cotidiano escolar transcorra de forma menos brusca, compreendendo a potência do conhecimento que é construído pelo professor no início de sua carreira e como tal processo repercute em todo o percurso de desenvolvimento profissional docente, auxiliando o professor a fazer suas escolhas e a construir sua prática pedagógica não pautado no constante improviso, isolamento e reprodução acrítica, mas baseado na troca e na reflexão das realidades e das possibilidades de atuação.

\section{"Eu fiz a escolha da docência do possível, sabe?! Não é a docência que eu defendo, mas é a docência possível!"}

Ensinar é uma atividade complexa que se desenvolve em teias históricas, culturais, sociais e políticas (COCHRAN SMITH, 2003, p. 4). Nesse sentido, uma atividade complexa não possui um processo de formação simples, que dará conta de todas as nuances dos variados contextos de atuação docente.

Assim, compreendemos, tal como Huberman (1995), Lima (2007) e Marcelo (2009) a formação docente de modo contínuo, consistindo em uma construção no decorrer da trajetória do sujeito. Desse modo, não se trata de uma série de eventos, mas de um percurso integrado, orgânico e confluente de saberes e fazeres em torno do processo ensino-aprendizagem, objeto que especifica a função docente, conforme defende 
Roldão (2007), que define identitariamente o professor e o qualifica para o desempenho da sua responsabilidade profissional.

Aprender a ensinar acontece com o tempo, não exclusivamente em um período de formação inicial, pois "aprender a ensinar é um processo, não um evento". (COCHAN-SMITH, 2012, p. 12). Nesse sentido, a formação inicial não dará conta de toda complexidade que a docência amalgama, no entanto poderá favorecer as condições para que o professor compreenda a complexidade do exercício da prática profissional docente.

Na voz das professoras depoentes é possível depreender essa visão, do seguinte modo:

[...] a gente não sabe de tudo, a gente não vai dar conta de tudo, a gente aprende muito também assim com eles né e isso, de certa forma eu relaxei um pouco, assim, porque eu entendi que eu não vou.... não vou ter resposta pra tudo e não tem o menor problema dizer que não sei... (Professora A - 16/04/2019).

Então isso (saber que eu vou continuar aprendendo), de certa forma, me conforta, assim porque - é isso - eu entendo que eu ainda vou me transformar ao longo do tempo, como professora, e transformar em vários sentidos, não quer dizer que eu vá sempre melhorar, mas eu acho que eu vou me transformar porque a docência te coloca muitos desafios mas eu hoje, eu tenho muita confiança, assim, no tipo de professora que eu quero ser...( Professora F - 27/08/2019.)

Embora as professoras relatem que a consciência de que não saberão tudo Ihes confere confiança, há nos primeiros anos do exercício da atividade docente sentimentos plurais de "sobrevivência e descoberta" (HUBERMAN, 1995) que podem gerar ansiedades e tensões no professor iniciante. Isso se justifica, segundo Alarcão e Roldão (2014), porque a inserção profissional acontece sem acompanhamento, de forma abrupta, por vezes, com dificuldades que, dependendo do contexto e do caso, podem gerar desmotivação, desencanto, desilusão e até o abandono da carreira.

Esse período inicial é marcado pela ansiedade gerada em torno do desconhecido e no contraste entre o que é idealizado pelo sujeito e a realidade encontrada; entre o esperado e o cotidiano docente, além do desenvolvimento de um senso de responsabilidade que está contido na teia do desenvolvimento profissional e da construção da identidade profissional. Neste processo - que não é uniforme - há um caminho de construção e desconstrução, de aprender; desaprender e reaprender.

O processo de construção do eu profissional é de tal forma complexo que não se encerra e nem se inicia na formação inicial. Ele envolve experiências anteriores do professor, sua formação inicial, suas idealizações, o confronto destas com a realidade, marcada por tentativas, erros e reflexões. Por tudo isso, este processo de desenvolvimento profissional não é linear ou homogêneo, tal como se pode depreender das falas a seguir:

E aí eu fui tentando moldar uma professora, que hoje eu não me reconheço [...]. E aí... eu fui assim..." como é que eu vou fazer, né?!" a questão do falar, de ter que se impor, porque assim... eu comecei a ficar no desespero. Eu fui tentando essa via do diálogo e da afetividade e foi dando tudo errado (...) E aí eu comecei a gritar muito! (...) porque era um desespero e eu não sabia o que fazer. Então eu falei: "isso também não vai dar certo!". A verdade é que fui endurecendo! (...) Como te disse eu tô fazendo a docência... eu fiz a escolha do possível, sabe? Não é a docência que eu defendo, mas é a docência possível! Para que eu sobreviva enquanto professora e para que eu tenha condições de dar aula...a verdade é essa! É... se eu pudesse, eu seria diferente! Mas eu não posso! (Professora C - 21/06/2019) 
Assim, eu rebatia muito sabe?! E "vai ficar sem isso, sem aquilo!". Já vi que... que não é um caminho que dá muito certo! Esse começo serviu como experiência pra eu saber o que não fazer! (Professora D - 22/07/2019)

As narrativas das professoras C e D evidenciam algumas estratégias e tentativas que foram lançando mão em seu período de inserção e que, de algum modo, contribuíram para que percebessem o seu "endurecimento" enquanto professora. Suas narrativas, no entanto, não se encerram neste ponto, visto que as professoras relataram que essas reações não se articulavam com seus princípios pedagógicos e dessa forma tinham chance de pôr em confronto suas concepções, idealizações e a realidade e, consequentemente, o seu "eu profissional. A professora " $\mathrm{C}$ " diz estar construindo a "docência do possível", isto é, a docência mais próxima do que ela defende frente ao cotidiano com o qual ela lida.

Assim, no processo de inserção profissional o professor vivencia um balanceamento entre o idealismo oriundo da trajetória do sujeito e de sua formação inicial e o realismo das demandas do contexto profissional, tal como afirmam Alarcão e Roldão (2014), configurando-se como um processo de reorientação interna que pode ser auxiliado externamente. Desse modo, há a necessidade de uma inserção intencionalmente assistida, atentando para que a socialização profissional não seja uniformizante e rígida, mas compreendendo as dimensões da criatividade e da subjetividade do sujeito.

Nesse sentido, o professor iniciante possui suas idealizações oriundas de distintas fontes, como sua experiência anterior como aluno, sua subjetividade e sua formação inicial. No confronto com a realidade do cotidiano da sala de aula e suas demandas se percebe em um complexo desafio de balancear estas dimensões, a saber: do idealismo e da realidade. O que defendemos é que no enfrentamento deste desafio o docente não esteja sozinho, mas que vivencie este momento sistemática e intencionalmente assistido, de modo que as trocas, que são tão potentes, não decorram apenas de modo espontâneo.

\section{"É muito bacana esse espaço de trocar"}

Frente às questões desafiadoras podem existir múltiplas reações, tais como a inércia, sucumbir aos dilemas cotidianos ou enfrentá-los de modo reflexivo e dialógico. Nas falas das professoras participantes da pesquisa foi possível perceber que embora suas inquietações existam, suas formas de enfrentá-las se afinam com uma postura de reflexão sobre a prática e não de acomodação ou estabilização. Nesse sentido, optamos pelo uso do termo inquietação, buscando identificar os desafios, mas salientando os enfrentamentos deles decorrentes.

Apesar de todas as inquietações apresentadas no início da carreira, neste período há aprendizagens intensas provenientes de distintas fontes, tal como Lima (2007) aponta, destacando a criação de uma "rede de ajudas" e de troca como uma dessas fontes.

Nas narrativas docentes a relação com os pares foi apresentada como a forma mais recorrente de enfrentamento das inquietações. Essa troca favoreceu os processos de descoberta e desenvolvimento profissional das professoras mesmo sem um aparato institucional.

Ao se referirem a essa troca, mesmo que por vias espontâneas e não institucionais, as docentes nos apresentam a necessidade de uma importante problematização: a indispensabilidade da criação de espaços para 
que as trocas entre os pares tenham um apoio institucional, bem como políticas que as favoreçam, dada sua imprescindibilidade para a formação e desenvolvimento profissional do professor.

A colaboração e a troca entre os pares fazem a diferença na permanência do professor em situação de inserção profissional na carreira docente, pois compreendem a importância de superar o isolamento à medida que essa partilha ocorre. Essa perspectiva é corroborada por Alarcão e Roldão (2014, p. 112), que defendem a colaboração entre os colegas, como "meio de ultrapassar as dificuldades num processo de socialização que se consubstancia através de conversas, sugestões, confrontos de estratégias, partilha de dificuldades e soluções".

Nessa direção, as professoras apresentaram o apoio dos pares como forma de enfrentar seus desafios:

Cheguei de paraquedas, aí você recebendo doação de professores, de colegas. "Toma, eu tenho isso pra doar," "Eu tenho isso", e você vai montando. Aos poucos você vai... (Professora B - 18/04/2019)

Quando eu cheguei, eu conversei com uma professora lá... que é muito boa alfabetizadora! Então eu cheguei, deu cinco horas, a escola fechando e a gente conversando... Ela me deu os cadernos dela, eu xeroquei, eu falei "me dá isso aqui pelo amor do Senhor!". (risos). Fui lá, já xeroquei e eu monto o meu. (Professora D - 22/07/2019).

Mas é bom porque lá eles trocam né, eu tenho essa ajuda! "Ah... tô precisando isso... como é que eu faço? Me dá uma ideia...," "Ah...tô pensando em fazer uma atividade...dá uma ideia aí..." ou às vezes você fala: "Ah, tava pensando em fazer assim, assim... ou fazer isso", aí a pessoa fala: " não... a gente podia fazer isso...assim, assim...assado...." E a gente vai trocando... (Professora E - 25/07/2019.)

A importância dessa troca é tão evidenciada nos relatos docentes que uma das professoras menciona que sua rota de retorno para sua residência após as aulas era completamente alterada de modo que ela pudesse trocar ainda mais com outra professora.

[...] Eu pegava carona com ela (uma professora mais experiente), fora do meu trajeto, mudava meu trajeto completamente só pra trocar com ela. Uma vez tava sentada... eu... eu... só queria ouvir! Então, uma conversa - às vezes de vinte minutos - te faz ver coisas que você ia levar anos pra aprender. Eu ficava... porque às vezes eu nem queria ir com a carona, assim, não tinha intenção e ela perguntava "você vai embora agora? Quer carona?". E aí eu já tava indo embora pra pegar minha condução normal e mudava completamente (risos) porque a gente ia trocando. (Professora $E-25 / 07 / 2019$ ).

A ênfase dada para a importância da partilha nos permite pensar sobre a necessidade de favorecer que essa troca se desenvolva com maior frequência no cotidiano, extrapolando o caráter informal, por meio de políticas de formação docente que preconizem essa troca como parte do percurso formativo, posto que:

acreditamos que privilegiar na formação de professores a imersão na prática pressupõe a criação de situações em que professores em formação inicial e professores experientes possam pensar, investigar, refletir e trocar saberes sobre o que os constitui como docentes: seu trabalho. Não se trata, portanto, de meramente aumentar o tempo dos licenciandos na escola, mas de qualificar este tempo, privilegiar outros protagonismos, criar novos cenários, proporcionar outros tipos de experiência e convivência. (CAMPELO; CRUZ, 2019, p. 171). 
Tal concepção passa pelo entendimento de que a docência é marcada pelo isolamento, em que o professor com suas portas fechadas trabalha com sua turma e que há a necessidade do que Cochran-Smith (2003) nomeou por processo de "desprivatização da prática", que consiste na interrupção do ensino como ato privado. É importante destacarmos que, em nossa perspectiva, esse isolamento não é uma opção exclusivamente escolhida pelo docente, uma vez que seu contexto - em linhas gerais - dificulta a existência das trocas tornando escassos os espaços de planejamento coletivo, quando existentes; com quantitativo elevado de alunos por turmas; demandas burocráticas e a necessidade de trabalhar em mais de uma escola para complementarem suas rendas.

Nesse sentido, é importante que haja a qualificação do tempo na escola dos licenciandos e a compreensão da importância do início da carreira no desenvolvimento da mesma, favorecendo cada vez mais as trocas que impactam na continuidade do profissional na carreira e na edificação do conhecimento da prática, isto é, a concepção que defende que os docentes tratem suas salas de aula como espaços de investigação e formação, os conhecimentos gerados como propiciadores de novas questões em um movimento de aprendizagem da docência de modo intencional. (Cochran-Smith, 2012).

Para além da articulação da troca entre os pares e a permanência na docência expostas pelas professoras entrevistadas, são mencionadas como elementos importantes para a continuidade na profissão: a possibilidade de observar o processo de construção do conhecimento, as defesas constituídas ao longo da formação inicial e no desenvolvimento profissional, fazendo as docentes elaborarem uma perspectiva de professoras que almejavam ser, a despeito de, no confronto com o cotidiano, essas visões sofrerem modificações.

Foi uma coisa que fiquei pensando "como é que eu sobrevivi àquele ano (o primeiro ano da inserção)?", né, eu fiquei tentando... eu acho que a questão de tentar, de não desistir de tentar, fazer aquilo que você, que você acredita que você defende enquanto educação foi um pouco o que me sustentou no início de carreira. (Professora C - 21/06/2019)

Eu acho que ao longo do meu curso da Pedagogia, da graduação e das experiências que eu tive, todas elas...da escola, dos professores supervisores que eu tive no PIBID, dos professores que eu pude acompanhar nos estágios isso me ensinou e me formou pra que eu tivesse já é...elaborada a concepção de ensino que eu tenho hoje...Então eu...isso pra mim, eu acho que é minha....que palavra eu posso usar? Acho que é o que eu tenho de mais confiante, de mais seguro! Eu sei hoje a professora que eu quero ser! Não é que eu sou cem por cento do tempo, porque eu não consigo! Mas eu diria que sou boa parte! Isso me sustenta (Professora F - 27/08/2019)

Nesse sentido, embora esse início possa parecer assustador, como mencionado pela professora A, e abarcar uma série de desafios, os professores desenvolvem formas de enfrentamento que tem a troca com os pares como recurso do qual se utilizam mesmo que de modo espontâneo. Não obstante a complexidade deste período ele pode representar uma fonte potente no processo de desenvolvimento profissional do professor. 


\section{Considerações Finais}

O estudo das inquietações de professoras iniciantes permitiu refletir sobre aspectos que se articulam com a formação inicial e à subjetividade inerente a construção do eu profissional. No presente artigo foram discutidas inicialmente as complexidades da inserção profissional, a partir das expressões utilizadas pelas docentes sobre o início da carreira e de suas inquietações, explorando de modo tangencial as questões acerca da alfabetização, visto que optamos por um recorte que privilegiou as discussões da questões da inserção profissional; em seguida, o balanceamento entre as expectativas das professoras e a realidade por elas encontradas e, por fim, analisamos o papel da troca entre os pares no processo de desenvolvimento profissional do professor bem como a necessidade de que essa troca não se dê apenas de forma espontânea, mas que se constitua por vias institucionais, dada sua importância no processo de formação do professor que - em nossa compreensão - é continuo.

As narrativas docentes propiciam a reflexão sobre o quão desafiador pode ser para um professor equalizar suas perspectivas e o cotidiano e como a mudança é constitutiva da profissão docente. Nesse sentido, o docente precisa se movimentar para lidar com os sujeitos com o quais se relacionam que são diversos e heterogêneos para que o ensino seja significativo. Este percurso do desenvolvimento profissional não é linear ou isento de desafios e dilemas.

Frente a esses dilemas, a troca entre os pares foi mencionada por todas as professoras como uma forma de enfrentamento. Tais menções nos fazem pensar a respeito da necessidade dessa "rede de ajudas" (LIMA, 2007) e da necessidade de que ela não seja fortuita. É necessário que os professores tenham desde a formação inicial o hábito de partilhar, construindo aprendizagens que serão significativas para sua trajetória, para além dessa questão, a inserção profissional deve ser acompanhada com ações intencionais e sistemáticas por meio de uma troca com professores mais experientes, transcendendo o isolamento característico da profissão. Visto que esse isolamento é prejudicial para o processo de inserção do professor bem como para a aprendizagem dos educandos.

Para tal, é preciso que os docentes possuam espaço em seu cotidiano para refletirem coletivamente sobre suas práticas; trocarem experiências e serem acompanhados em seu período de inserção profissional, uma vez que a aprendizagem da docência se dá com o tempo pelo trabalho de novos professores acompanhados por colegas mais experientes em um movimento de continuar aprendendo e fazendo aprender. (COCHRANSMITH \& LYTLE, 1999). Utilizamos o gerúndio dada a continuidade do processo de aprendizagem na profissão docente.

É necessário que esse movimento de troca a inserção profissional intencionalmente assistida seja alvo de atenção das políticas públicas e no cotidiano escolar para que esses professores iniciantes não tenham que contar exclusivamente com o caráter espontâneo da partilha e que ela não fique relegada à momentos esporádicos, mas que seja incorporada ao cotidiano dado seu caráter formativo e relevante para a aprendizagem docente e para a aprendizagem discente, uma vez que ambas são afetadas pelo ingresso desassistido dos sujeitos no magistério.

No decorrer da pesquisa novas questões foram suscitadas que podem favorecer a continuidade dos estudos a respeito da inserção profissional: quais sentimentos interpelam licenciandos ao concluírem a graduação, como eles são construídos e como se articulam com o cotidiano escolar? Quais impactos da incorporação da troca entre os pares desde a formação inicial no desenvolvimento profissional do professor? Como as urgências da escola se articulam com as práticas desenvolvidas no âmbito da formação inicial? 
Desse modo, consideramos importante um olhar atento para o que inquieta o professor em situação de inserção profissional, uma vez que esse período tem papel importante no desenvolvimento profissional do professor. O início pode até ser "assustador", "tenso" e "desafiador" - conforme apontado pelas professoras colaboradoras de nossa pesquisa - mas também é um período de aprendizagem intensas que precisa ser sistemática e intencionalmente assistido. 


\section{REFERÊNCIAS}

ALARCÃO, I.; ROLDÃO, M. C. Um passo importante no Desenvolvimento profissional dos Professores: o ano de indução. Formação Docente. Revista Brasileira de Pesquisa de Formação de Professores, Belo Horizonte, v. 06, n. 11, p. 109-126, ago./dez. 2014.

ANDRÉ, Marli. Inserção profissional de egressos de programas de iniciação à docência.

Relatório de Pesquisa Interinstitucional. Brasília: CNPq, 2018.

COCHRAN-SMITH, M; LYTLE, S.L. Relationships of knowledge and practice: teacher learning in communities. Review of Research in Education, London: Sage, n. 24, p. 249-305, 1999.

COCHRAN-SMITH, M. Aprendizagem e de saprendizagem: a formação de professores educadores. Teaching e Teacher Education, v. 19, p. 5-28, 2003.

Um conto de duas professoras: aprendendo a ensinar com o tempo. Kappa Delta Pi Record, v. 48, p. 108-122, 2012.

GALVÃO, C. Narrativas em Educação.Ciência \& Educação, v. 11, n. 2, p. 327-345, 2005.

GOULART, C. O conceito de letramento em questão: por uma perspectiva discursiva da alfabetização. Bakhtiniana, São Paulo, 9 (2): 35-51, Ago./Dez. 2014

GOULART, C.M. A apropriação da linguagem escrita e o trabalho alfabetizador na escola. Cadernos de Pesquisa, n. 106, São Paulo, Fundação Carlos Chagas, p. 172-186, jun., 2000.

HUBERMAN, M. O ciclo de vida profissional dos professores.In: NÓVOA, António (Coord.). Vidas de professores. Porto/Portugal: Porto, p. 31-78, 1995.

LIMA, E. E. et al. Sobrevivendo ao início da carreira docente e permanecendo nela: Como? Por quê? O que dizem alguns estudos. Educação e linguagem, São Paulo, v. 10, n.15, p. 138-160. jan./jun. 2007.

MARCELO, C. Formação de professores - para uma mudança educativa. Porto: Porto Editora. 1999.

MARCELO, C. Desenvolvimento profissional docente: passado e futuro. Sísifo: Revista de Ciências da Educação, n. 8, p. 7-22, jan./abr. 2009.

ROLDÃO, Maria do Céu. Função docente: natureza e construção do conhecimento profissional. Revista Brasileira de Educação. v. 12, n. 34, jan./abr. 2007.

TARDIF, M. A profissionalização do ensino passados trinta anos: dois passos para a frente, três para trás. Educação \& Sociedade. Campinas: CEDES, v. 34, n. 123, p. 551-571, abr.-jun. 2013. Disponível em: <http:// www.cedes.unicamp.br>. Acesso: 23 de maio de 2019.

TARDIF, M.; RAYMOND, D. Saberes, tempo e aprendizagem do trabalho no magistério. Educação \& Sociedade. Ano XXI, n. 7

FERNANDES, I. C. B.; CRUZ, G. B.; “O Início é até meio assustador (...)!": Inquietações docentes pela ótica de professoras iniciantes Formação Docente - Revista Brasileira de Pesquisa sobre Formação de Professores. Belo Horizonte. Vol. 13, no. 26 (p. 31-44) 30 abr. 2021. ISSN: 2176-4360. DOI https://doi.org/10.31639/rbpfp.v13i26.431 